\title{
Survey of Academic Library Consortia in the U.S.
}

\begin{abstract}
In 1970 USOE initiated a nationwide study of academic library consortia. The purpose of the study, carried out by SDC, was to develop a fund of descriptive and prescriptive information about library consortium activities. The study involved a questionnaire survey to identify and describe all known consortia, and a case-study analysis of fifteen selected consortia. This paper discusses the survey methodology, the findings, and two major products: $a$ Directory of Academic Library Consortia, and Guidelines for the Development of Academic Library Consortia. The latter presents a twenty-four step process that may serve as a useful model for library consortium development.
\end{abstract}

$I$

NTERLIBRARY COOPERATION is not a new phenomenon. Awareness of the vast and growing world literature, in relation to the holdings and resources of any single library, has fostered among librarians an acute appreciation of the interdependence of most of the nation's libraries and of the requirement for some level of cooperation.

In recent years there has been a strong movement toward formal arrangements for sharing library resources. Although these arrangements can be described in a variety of ways, the resulting organizations are usually referred to as consortia or networks. In contrast to the simple and largely informal arrangements for interlibrary loan, consortium or network arrangements require that members share system planning and development resources, as well as operating responsibilities and functions.

Carlos A. Cuadra is with the System Development Corporation. Ruth J. Patrick is at the University of California at Berkeley.
Although acceptance and implementation of library consortia have increased, little guidance has been available to libraries interested in exploring the idea-no design data, no standards, and no models upon which institutions might base better library service through joint efforts. In fact, there has been a dearth of good descriptive data on library consortia. To help remedy this situation, the U.S. Office of Education (USOE) contracted with System Development Corporation (SDC) to undertake a study of academic library consortia. A major purpose of this project was to analyze the usefulness and effectiveness of various patterns of library cooperation and to devise practical guidelines for improving the planning, development, and operation of academic library consortia.

\section{Survey Procedures}

Project methodology was designed to accomplish two major tasks:

1. Plan and carry out a broad-scale survey to identify and describe all consortia in American higher education that include libraries as a 


\section{2 / College \& Research Libraries • July 1972}

significant component.

2. Conduct in-depth analysis of selected library consortia to discover salient characteristics, similarities and differences, achievements and problems-and the ways in which these are interrelated.

Each of these tasks was to lead to a major product. The first was a Directory identifying all known library consortia in higher education and listing their components (participating libraries) and characteristics. The second was a comprehensive Guidelines document presenting a basic model for planning, developing, operating, and evaluating library consortia in higher education. This document was to be based on the findings from both of the major project tasks.

\section{Identification of Existing Academic Library Consortia}

To identify the universe of academic library consortia, a questionnaire (Q1) was sent to 2,600 colleges and universities throughout the United States asking the recipients for the names and addresses of consortia in which they held membership. It also included three items asking nonconsortium libraries about any prior experience with consortia and about their attitude toward possible future participation in cooperative activities. The purpose of the latter questions was to provide a basis for identifying and adding new participants to the Directory, should it be decided to update the Directory in a year or two.

Of the 2,600 QI's mailed, 1,000 were returned within four weeks following the initial mailing. A follow-up mailing, sent to the 1,600 colleges and universities

\footnotetext{
- Of the 783 Q1 respondents who did not belong to a consortium, 216 gave their reasons for nonmembership. The three most mentioned reasons were lack of need (fifty-eight libraries), prohibitive cost (thirty-six libraries), and administrative difficulties (thirty-three libraries). Some libraries mentioned that no one had ever proposed membership to them.
}

that had not responded, resulted in an additional 516 returns, for a total of 1,516 . Of the 1,516 libraries responding, 698 or forty-six percent reflected participation in some kind of cooperative activity. ${ }^{\circ}$ Of these, 409 were identified as possible academic library consortia, and these became the target audience for a second, more detailed questionnaire (Q2).

The total number of Q2's returned to SDC was 173. The other 236 groups not filling out a Q2 indicated either by letter or telephone that they were not academic library consortia or that they were otherwise outside the scope of the study.

In the process of screening the 173 returned Q2's, it became necessary to tighten the definition of "academic library consortium" in order to decide which groups should be included in the directory. To comply with the original intentions of USOE, the project staff developed the following six criteria for inclusion in the Directory:

1. The cooperative must be organized voluntarily to pursue activities of benefit to the academic participants involved.

2. The participating institutions must be autonomous; that is, they must report to separate Boards of Regents or other separate, higher level governing bodies.

3. More than half the members of the group must be academic libraries.

4. Two or more libraries must be involved, with activities extending beyond traditional interlibrary loan as defined by ALA rules.

5. If the library cooperative is part of a higher level, multipurpose higher education consortium, it must be a separate entity with the goal of improving library service.

6. The consortium must have developed beyond the exploratory stage, i.e., the group must have declared itself a cooperative en- 
tity and must at least be planning joint activities.

Application of these criteria resulted in the elimination of forty-nine Q2 returns, leaving 125 academic library consortia for inclusion in the Directory.

In preparing the Directory, the data for each consortium were first edited for completeness and then keyboarded directly from the questionnaire on an IBM Magnetic Tape Selectric Typewriter. A draft of each entry was sent to the subject with an accompanying letter and checklist requesting that the entry be reviewed and any missing material added. Ninety percent of the entries in the Directory responded with updated drafts and/or missing information. Any further questions were resolved with follow-up phone calls.

The survey procedures followed make it highly likely that a very high percentage-if not all-of the existing academic library consortia in the U.S. were identified and that their entries in the Directory of Academic Library Consortia are accurate and complete.

\section{The In-Depth Case Studies}

The Q2 survey returns provided a wealth of information on various aspects of academic library consortia: objectives, financial planning, management and staffing, facilities, and problem-solving and evaluative techniques. To supplement this information and to provide more in-depth information on the problems and issues associated with consortium development, the project staff conducted a case-study analysis of fifteen selected groups. In selecting the subjects to be visited, careful consideration was given to the following variables and factors of interest, as reflected in the Q2 returns:

-Breadth and scope of the consortium's purpose and objectives

-Existence of centralized headquarters

-Number of members
-Geographic distance between participants

-Membership in multipurpose higher education consortia

-Amount, source, and stability of funding

-Homogeneity of participating libraries, e.g., with respect to type and size

-Length of existence

-Kinds of agreements and rules for participation

-Current mix of planned and operating activities

-Staffing patterns

-Views on problems and recommended solutions

-Extent of direct services from the headquarters facility (if any)

-Extent of automation

The final group of consortia selected by SDC and approved by USOE comprised:

-Associated Colleges of Central Kansas

-Collection and Evaluation of Materials on Black Americans

- Colorado Academic Libraries Book Processing Center

-Common Library of the Graduate Theological Union

-Consortium of Universities

-Consortium of Western Colleges and Universities

-Dayton-Miami Valley Consortium Libraries

-Five Associated University Libraries (FAUL)

-Kansas City Regional Council for Higher Education (KCRCHE)

-Mississippi Valley Libraries Cooperative Service

-New England Library Information Network (NELINET)

-New Hampshire College and University Council (NHCUC)

-Northwest Association of Private Colleges and Universities (NAPCU)

-Ohio College Library Center (OCLC) 
-Tri-State College Library Cooperative

The general plan in conducting the case-study analysis was to spend one day at the headquarters facility (if there was one) and one or two days following with one or two member libraries, with a follow-up visit to headquarters or extended visits to more member libraries, if necessary. The kinds of persons interviewed at the headquarters included the Director (or Coordinator or Chairman), the director of the board of trustees, staff members, and representatives of the State Library. If the library cooperative were part of an educational consortium, we contacted the Director of the educational consortium and/or the faculty member who represented the librarians to the educational group. At individual libraries, we interviewed directors and staff members of libraries that were currently members, and directors of libraries that had been members but had withdrawn from the consortium. The interviews varied in length from one to four and a half hours. In all, seventy persons were interviewed in the course of fifty-eight interviews.

To help ensure collection of all required information, as well as the best use of interviewers' and interviewees' time, two detailed field site visit checklists were developed and tested: one for headquarters, and one for individual library members. The checklist for headquarters devoted approximately half of its coverage to planning and development, and the other half to operational matters, including purposes and objectives, financial support activities, facilities, personnel and management, and evaluation and measurement. The checklist for library members covered a more limited range of topics, focusing on the benefits to the library from participation and the problems associated with participation. Wherever possible, evaluative information provided by the headquarters was cross-checked with that of individual library members, to ensure that the case-study analysis reflected both perspectives.

The first group of visits to five consortia was conducted in the summer of 1970. These groups had been suggested by USOE and available preliminary information had suggested that they would indeed provide rewarding visits. These visits, carried out before Q2 survey returns were available, helped to test and refine the field site visit checklists.

Most of the field site interviews were carried out by a team of two librarians/ system analysts, with tape recorder backup; several were conducted by one librarian/analyst and a few, early in the project, were conducted by three project staff members as a training exercise, and as an aid in defining the most uniform and productive interview procedures. The tape recordings were transcribed, and copies of the transcripts keyed for later analysis in connection with the Guidelines document.

It should be mentioned that those interviewed were extraordinarily cooperative. They recognized the importance of helping other libraries to avoid some of the problems that they themselves had encountered and were, therefore, quite candid in identifying their major problems and in suggesting ways in which others could avoid or minimize similar problems. One consortium director almost insisted on the project team's talking to a particular member library that was quite disenchanted with the group's progress, as well as with libraries that were very well satisfied. This was consistent with our general procedure, which was to attempt to interview both satisfied and dissatisfied member libraries.

\section{Findings AND IMPLiCATIONS}

\section{Range and Scope of Consortium Activities}

The cooperative activities in which the greatest number of academic library 
TABLE 1

List of Librany Consortium Activities

\begin{tabular}{lcccc}
\hline \hline \multicolumn{1}{c}{ Activity } & $\begin{array}{c}\text { Number of Consortia } \\
\text { Currently } \\
\text { Operating Activity }\end{array}$ & Percent & $\begin{array}{c}\text { Number of Consortia } \\
\text { Planning or } \\
\text { Developing Activity }\end{array}$ & Percent \\
\hline Reciprocal borrowing privileges & 97 & $78 \%$ & 4 & $3 \%$ \\
Expanded interlibrary loan service & 80 & 64 & 9 & 7 \\
Union catalogs or lists & 78 & 62 & 24 & 19 \\
Photocopying services & 72 & 58 & 11 & 9 \\
Reference services & 50 & 40 & 16 & 13 \\
Delivery services & 44 & 35 & 14 & 11 \\
Mutual notification of purchase & 40 & 32 & 23 & 18 \\
Special communications services & 35 & 28 & 12 & 10 \\
Publication program & 34 & 27 & 14 & 11 \\
Catalog card production & 34 & 27 & 12 & 10 \\
(Other) Cataloging support & 33 & 26 & 18 & 23 \\
Joint purchasing of materials & 30 & 24 & 29 & 26 \\
Assigned subject specialization in & & & \\
acquisition & 28 & 22 & 33 & 17 \\
(Other) Acquisitions activities & 22 & 18 & 21 & 9 \\
Microfilming & 21 & 17 & 9 & 13 \\
Central resource or storage center & 21 & 17 & 11 & 14 \\
Bibliographic center & 17 & 14 & 16 & 10 \\
Joint research projects & 17 & 14 & 18 & 17 \\
Clearinghouse & 15 & 12 & 13 & 5 \\
Personnel training & 15 & 12 & 21 & 3 \\
User orientation programs & 14 & 11 & 13 & 6 \\
Other & 9 & 7 & 4 & \\
Bindery services & 7 & 6 & 5 & \\
Recruitment programs & 6 & 5 & &
\end{tabular}

consortia are currently engaged (see Table 1) are reciprocal borrowing privileges, expanded interlibrary loan services, the production of union catalogs or lists, and photocopying services. These activities typically involve low cost and low levels of required compromise among member libraries, and they provide fairly immediate benefits. In contrast, relatively few groups are engaged in activities, such as computerized catalogcard production, that require large initial financial investment, long lead times before benefits are realized, and hard-to-reach agreement on practices and standards. The cooperative activities being undertaken by cooperatives are described in greater detail in the Guidelines document.

\section{Financial Support}

The mean funding level of forty-seven consortia who reported their budgets is $\$ 75,000$, with fifty percent (eighteen percent of the total) reporting that they operate on budgets of less than $\$ 75,000$. Interestingly enough, fifty-four percent of the respondents report that they have no formal budget. Judging from the sample, members of consortia that have no identifiable budget carry out cooperative activities with their regular staff and do not know how much the activity is actually costing.

The two major patterns of funding are internal (consortium members) and external (federal, state, or municipal government, or foundations). Internal funding is obtained from dues paid by members, from fees for services or products, or both.

1. Dues. Dues from member libraries or their parent institutions comprise the major funding source for approximately forty-two percent of the total budgets for sixty-one responding groups. Membership dues vary ranging from $\$ 25.00$ per mem- 
ber (to cover postage and stationery) to $\$ 10,000$ (to cover research and development of computerized library systems).

2. Fees. Service fees from member libraries or their parent institutions represent ten percent of the source of major funding. Service fees from individual users represent two percent. One problem that library groups experience when this methof funding is employed is maintaining a stable level of activity of operations until all fees are received.

3. Dues and Fees, Combined. Only five of the library cooperatives indicated that their funds are based on dues paid by members as well as fees for services or products.

External funding is obtained through federal, state or municipal support. In addition, a library consortium may receive money from a larger educational consortium of which it is a member; this money might consist of Title IIIC funds, or of dues charged by the parent institution. Although external funding can be of great use, only thirty-two percent of all the funding for the sixty-one responding groups is from external sources. Attitudes about sources of funding varied. Some members we interviewed welcomed external funding because they felt it makes it easier for the libraries to achieve cooperation. More often, those interviewed felt that it was unwise to rely solely on external funding.

\section{Facilities}

The questionnaire survey of all 125 library consortia indicated that use of computer technology is limited: Only thirty-three groups (twenty-six percent) use a computer, with service being provided most commonly by a university computing center. There were only two instances in which the computer service was provided by the library consortium itself. The cooperatives were asked to indicate facilities and equipment spe- cifically acquired to support library consortium activities. The most frequently acquired items were office space (38 consortia), work space (28), telephone or teletype instruments (25), storage space (24), trucks or other transportation devices (21), and copying and/or microfilm equipment (14).

\section{Management and Staff}

The consortium director is responsible for providing the guidance and management control needed for the consortium to achieve its objectives.

The decision of whether or not to have a director depends on many factors, particularly on the range and scale of planned activities. Forty-one (thirtythree percent) of the 125 academic library consortia identified have directors, nearly all of whom are full-time. On the basis of the survey data, including the case-study interviews, it appears that a consortium is likely to need fulltime direction if a broad range of centralized activities is contemplated. Activities such as computerized technical processing require a concerted, sustained management effort. If the cooperative decides not to appoint a director, then his duties have to be divided among the library directors. In most consortia in the case-study sample, an elected chairman shared the work with the library directors.

A question that often arises when selecting a director is, "Should the director be selected from the staff of one of the member libraries?" Some librarians interviewed felt that it would be a disadvantage for the director to come from outside the system, because it would take too long for him to learn about the operations of the participating libraries. Others felt that if the director came from inside the system, members might feel that he was partial to the library with which he had been associated. The final decision really seems to depend on how the directors feel about the particu- 
lar candidates and their qualifications. Our observations, reinforced by comments from the literature, lead us to believe that, indeed, a special type of leadership is needed to provide effective direction to library consortia. Although made in reference to educational consortia, Paterson's statement $(9$, p.4) is applicable to library cooperatives: “. . . the kind of leadership needed for consortia calls for 'authority' to be based on the power of suggestion and persuasion-quite different from the traditional hierarchical leadership."

Relatively few consortia employ a significant number of full-time staff members. Most cooperative activities are carried out by the current library staff; separate staffing is employed only when special activities, such as technical processing, are undertaken. Interestingly enough, most consortia reported no difficulty in obtaining qualified personnel, when required.

\section{Nature of Interlibrary Relationships}

The questionnaire study, the case studies, and the literature on consortia (and networks) have revealed that the interrelationship of academic consortia -as well as academic libraries-is extremely complex. Figure 1 illustrates the interrelationships that were encountered in the study. For example, Library A is a member of an educational consortium, Consortium 2, the libraries of which are engaged in only one cooperative activity: the development of a specific subject area. Library $\mathrm{A}$ is also a member of an academic library consortium, Consortium 1 , that is in the process of providing extended interlibrary loan and reciprocal borrowing privileges, as well as considering other possible activities. Finally, Library A is also a member of an academic library consortium, Consortium 3, that is concerned with centralized technical processing. Furthermore, Library A has had the option (selected by one of its sister libraries) to be a member of Consortium 5, which consists of academic and public libraries. In the meantime, Consortium 3 is in the process of negotiating with Consortium 4 , in order to benefit from the latter's recent developmental accomplishments.

The results of the case studies suggest that most library consortia are in a state of flux, considering new activities and new cooperative arrangements for mutual benefit. It is interesting, therefore, that there is very little communication or coordination among groups. Many librarians were unaware of developments outside their consortium; this is understandable, since no directory or other comprehensive source of information about library consortia was in existence prior to the present USOE-sponsored study.

\section{Evaluation of Consortium Operations and Benefits}

Evaluation is, or should be, an important part of any cooperative's work. In the questionnaire survey, library consortia directors or chairmen were asked to indicate which techniques they used to evaluate the effectiveness of their library consortium activities. The results are shown in Table 2. The most often used evaluative technique consisted of informal feedback. More formal methods of evaluation were less frequently used.

During the in-depth studies, it was possible to gain better insight into how these various methods of evaluation were used, the activities for which they were most often used, and how well they worked, as well as some feeling for ways in which their use could be improved. Several groups evaluated the benefits of the increased library resources now available to users by totaling the collections of all the member libraries. One must question the value of this kind of evaluation. It may be impressive to state that the user now has access to $\mathrm{X}$ thousands of volumes, but the relevant question is, "Are these the resources the user 


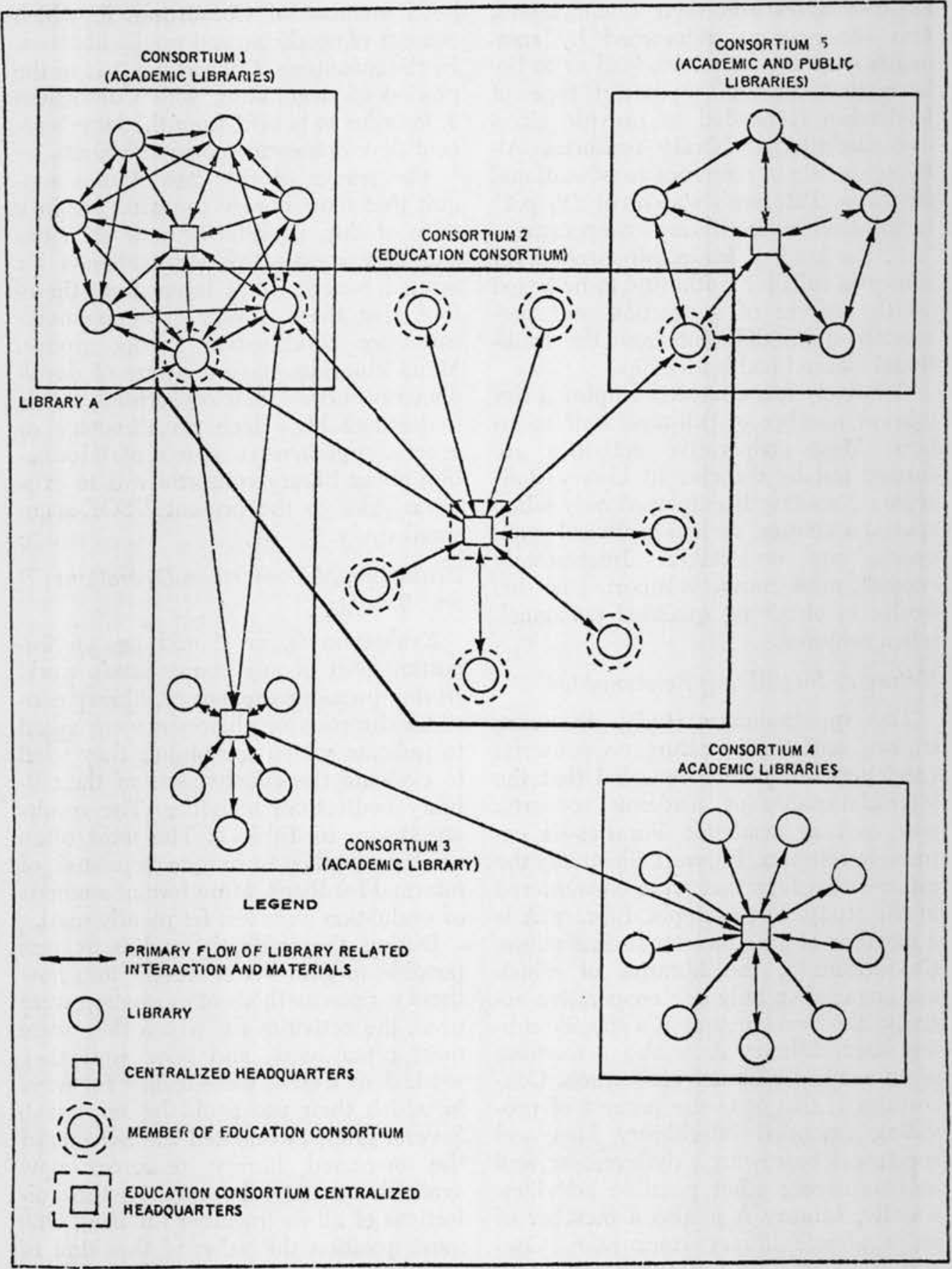

Figure 1

Possible Interrelationships of Libraries and Consortia (Simplified) 
TABLE 2

Techniques Used by Consortia to Evaluate Activity Effectiveness

\begin{tabular}{lcc}
\hline \hline \multicolumn{1}{c}{ Evaluation Technique } & $\begin{array}{c}\text { Number of Consortia } \\
\text { Using Technique }^{2}\end{array}$ & Percent \\
\hline Informal Feedback from Library Personnel Participating in & & \\
$\quad$ Consortium Activities & 82 & 66 \\
Informal Feedback from the Ultimate Users of Services & 61 & 49 \\
Analyses of Costs and Usage Statistics & 36 & 29 \\
Formal Surveys of Operations at the Participating Libraries & 26 & 21 \\
Operations Research Analyses (e.g. Work Flow, Cost & 16 & 13 \\
$\quad$ Effectiveness Tradeoffs) & 13 & 10 \\
Formal Surveys of the Ultimate Users of Consortium Services & 5 & 4 \\
Other & 33 & 26 \\
No Answer to Questionnaire Item & & \\
\hline
\end{tabular}

${ }^{1}$ Many consortia used several evaluation techniques.

needs, and is he using them?"

The more formalized methods of evaluation, such as analyses of cost and usage statistics, formal surveys of operations of the participating libraries and of users, and operations research analyses, were most often used by consortia engaged in large-scale computerized activities. This kind of evaluation was sometimes carried out by a consultant; in other instances, it was done by the headquarters staff, because an evaluation performed by outsiders was felt to be a possible cause of misunderstanding and dissension.

In addition to evaluating the effectiveness of specific activities, consortia need to make an overall evaluation of how well they are meeting their objectives. Most members interviewed felt that their consortium was successful, as judged by some of the following criteria:

1. Present members remained in the cooperative and continued to contribute time or money.

2. New members were joining.

3. Federal or other external funds were obtained.

4. The consortium had survived without external funds, or after external funds had ceased.

5. Activities were providing new and/ or improved services for the library users.

\section{Costs had been reduced.}

It is evident from the questionnaire survey and the in-depth case studies that evaluation of activities is not extensive. The survey also indicated that fifty-four percent have no identifiable budget. One likely interpretation is that librarians are participating in joint activities in addition to their regular library activities. Thus the time and money they have to plan, to develop, and to evaluate cooperative activities is limited. Although time may be limited-and, in fact, especially because time may be limited-it is vitally important that librarians make a careful evaluation of the costs and benefits of cooperative activities. By so doing they will help not only themselves, but also other libraries that might benefit from cooperative activities and that lack only the necessary descriptive and evaluative information to appraise their alternatives and take the next steps.

\section{Development Procedures}

The only adjective that aptly describes the approaches taken by academic library consortia in developing their activities is "diverse." Indeed, our initial conception of consortium development in terms of a fairly linear flow of activities proved to be optimistic. When several librarians were asked to relate their own developmental history 
to a sequence of steps distilled by the SDC staff from preliminary inquiries and from system planning theory, most of them commented that they had had to go through several of the steps several times.

The time required by consortia to achieve the final phase (Operation and Evaluation) varied tremendously and took, in some cases, up to fifteen years. In many cases it was easy to see, with hindsight, how the developmental cycle could have been shortened, even by a matter of years. With the wealth of experience that is now accessible through the Directory and the Guidelines documents, described in the next section, any group of interested libraries should be able to develop and move into operations in a relatively short time and with little or no wasted effort.

\section{Major Products of the Study}

As indicated earlier, two major products resulted from the study: the Directory of Academic Library Consortia, and the Guidelines for the Development of Academic Library Consortia.

\section{The Directory}

The Directory of Academic Library Consortia is a 290-page document, the main body of which comprises 125 entries describing currently known academic library consortia in the U.S. Each entry covers the following categories of information:

\begin{tabular}{|c|c|}
\hline Consortium & Special Services \\
\hline Name and Date & Conditions of Par- \\
\hline $\begin{array}{l}\text { Founded } \\
\text { Part Of }\end{array}$ & ticipation \\
\hline Area Served & and Source \\
\hline Participating & Staffing \\
\hline $\begin{array}{l}\text { braries and Year } \\
\text { Joined }\end{array}$ & $\begin{array}{l}\text { Advisory Boards } \\
\text { Publication }\end{array}$ \\
\hline $\begin{array}{l}\text { Purposes and Objec- } \\
\text { tives }\end{array}$ & $\begin{array}{l}\text { Headquarters } \\
\text { Information }\end{array}$ \\
\hline Current Activities & Source \\
\hline
\end{tabular}

The second part of the Directory consists of two statistical tables. The first provides an overview of all Directory entries along the dimensions of age, size, and membership, together with staffing and budget information and an indication of the kind of agreement upon which each consortium is founded. The second table displays the activities in which each consortium engages, thus providing an overall picture of the distribution of activities among the various cooperatives.

The third major part of the Directory comprises three indexes: the Directory Index, a State Index, and an Activity Index. Thus Directory users can easily identify consortia in their state or area that are engaged in particular kinds of activities of interest. By referring to the main entry one can also identify the appropriate contact point for further information. Judging by the cooperation received by the SDC project staff, interested libraries should be able to obtain a great deal of helpful information and advice.

\section{The Guidelines}

The Guidelines is a 200-page document intended to provide guidance for libraries that are forming or plan to form a consortium. Before discussing the content of the Guidelines a further comment on methodology is necessary.

In order to devise practical guidelines to improve the planning, development, and operation of academic library consortia, it seemed necessary to take full advantage of the knowledge and experience-both successful and unsuccessful - of existing consortia. Data from our initial site visits were used in conjunction with Grupe's procedural for education consortia to develop a first approximation of guidelines for academic library consortia. The initial guidelines were then discussed with persons at each consortium who were most familiar with its development. They were asked to com- 
ment on how well the guideline steps fit the actual development of their consortium, and to make suggestions, as a result of their experience, on how a consortium should be developed. Thus, while the recommended approach to development that is contained in the Guidelines is prescriptive, it is based, wherever possible, on the lessons gathered from real experiences, of actual groups. In those instances where procedures used could not be recommended, recommendations were made on the basis of an application of well-recognized principles of system analysis and project management.

We have identified four phases in the development process: Exploratory Phase, Planning Phase, Development Phase, and Operation and Evaluation Phase. Each phase can be subdivided further into a series of steps, shown in Figure 2. Each step is described in detail in the Guidelines. The information included under most of the steps is a combination of descriptive material-discussing the various ways in which the step has been accomplished by various consortia-the prescriptive material-recommending ways of accomplishing the steps that seem most desirable in the light of the evidence gathered during the study.

The developmental steps provided in the Guidelines are modular in that (1) not all steps are necessary for every consortium; (2) steps may be used in different sequences; (3) several steps may be performed simultaneously; and (4) steps tend to be iterated. For example, if members of an established consortium wish to undertake the development of a new activity, they would find it useful to cycle back through Steps 3,4 , and 5 in the Planning Phase, as well as most of the steps in the Development and Operation and Evaluation Phases. While, obviously, no single consortium-planning model or any recommended series of steps will fit the needs of every planning project, it can serve as a useful point of departure from which adjustments can be made to reflect local goals, resources, planning experience, and institutional receptivity. The model development process suggests that the Exploratory Phase could be carried out by most in two to four months, and the Planning Phase in from six to twelve months. We believe that these are reasonable estimates, provided that the cooperatives take full advantage of the experience now available to them. The Development Phase is, of course, the most highly variable, since it depends upon the particular activities undertaken, and the Operation and Evaluation Phase is essentially continuous and open-ended.

\section{Outlook for Future Development of ACADEMIC Library Consortia}

If one can judge from trends, academic library consortia are undoubtedly here to stay. Ninety-six of the 125 organizations that we studied were established between 1966 and 1970! Furthermore, the predicted continuing development of education consortia (Patterson, 9 , p. 3 ) suggests that more than a few librarians that are not now members of a consortium may, at some time in the future, receive memos from other college or university presidents informing them that they have become members of a consortium. One can even see faint glimmers of consortia of national scope. For example, several theological libraries have found it beneficial to merge their resources. Now, instead of being small libraries with small collections, the merged library is the third largest theological library in the country. This new library is working on cooperative arrangements with a large state university, as well as a large private university; it is also considering the development of a national network of theological libraries. This example is only one highlight of the exciting possibilities that exist for future growth and expansion. 




is

IN

2 
The pressure toward consortium development will certainly continue, at least until the nation provides more services analogous to the Library of Congress cataloging service (including MARC). One library consortium director expressed the need of national leadership in coordinating what has developed from this grass roots movement, in order to bring to fruition the electronic national library networks that have been forecast since the EDUCOM conference. As potential candidates for leadership he suggested the newly formed National Commission on Libraries and Information Science, EDUCOM, or the Library of Congress. Furthermore, the efforts of academic library consortia have to be considered in relation to other library consortia (e.g., special, public, and mixed), as well as in relation to comprehensive state network plans such as are being proposed in several states.

Barring the establishment of a national library system, which is certainly years -if not decades-away, the survival of many small private colleges is being threatened by the economic recession. Since many of these libraries cannot provide adequate service to their users, arrangements for cooperation among themselves or with other institutions may become mandatory. There is also increasing pressure on libraries to support new methods of instruction that-at least in some institutions-are causing students to become more independent in their use of the library and, as a consequence, are creating a demand for an even broader collection of library material for use in individual research. But it is clear that most affluent academic libraries cannot possibly acquire sufficient portions of the world's available literature to satisfy all their user groups; in fact, they must begin to delimit the fields of knowledge in which they will build extensive library collections. As this occurs, they will be forced to rely more and more on access, through reciprocal arrangements, to the specialized collections of companion libraries.

Given the viability of academic library consortia, the challenge is to find -and use-efficient means of establishing collective operations where there is clear need and strong interest. We believe that the two major tools developed from the present study should be of considerable aid in this regard.

\section{REFERENCES}

1. Cuadra, Carlos A. Phase I Progress Report on Study of Academic Library Consortia, System Development Corperation, TM-4597, August 1970.

2. Cuadra, Carlos A.; DeLanoy, Diana D.; Patrick, Ruth J.; and Mantius, Kean. Final Report on Phase II Study of Academic Library Consortia, System Development Corporation, TM-4597/004, November 1971.

3. DeLanoy, Diana D., and Cuadra, Carlos A. Phase II Progress Report on Study of Academic Library Consortia, System Development Corporation, TM-4597/001, August 1971.

4. DeLanoy, Diana D., and Cuadra, Carlos A. Directory of Academic Library Consortia, System Development Corporation, TM-4597/003/00, September 1971.

5. DeLanoy, Diana D., and Cuadra, Carlos A. Phase I Final Report on Study of Academic Library Consortia, System Development Corporation, TM-4597/002, 1971.

6. Five Associated University Libraries. In- terlibrary access: a two-year report of the FAUL access committee, Five Associated University Libraries, Syracuse, 1968-1970.

7. Grupe, Fritz H. "The Establishment of Collegiate Cooperative Centers," Ph.D. dissertation, State University of New York, Albany, August 1969.

8. Patrick, Ruth J. Guidelines for the DeSystem Development Corporation, TM4597/005, November 1971.

9. Patterson, Lewis D. Consortia in American Higher Education, Report 7, November 1970, ERIC Clearinghouse on Higher Education, Washington, D.C., 1970.

10. Sagan, Edgar L. "A Network Model for Planning and Establishing Higher Education Consortiums," Ph.D. dissertation, Ohio State University, 1969.

11. Schatz, Sharon. "Facsimile Transmission in Libraries: a State-of-the-Art Survey," Library Resources and Technical Services, 12:5-15 Winter 1968. velopment of Academic Library Consortia, 